\title{
Upper Airway Variation and Frequent Alcohol Consumption Can Affect Compliance With Continuous Positive Airway Pressure
}

\author{
Jong In Jeong ${ }^{1} \cdot$ Hyo Yeol Kim² Sang Duk Hong ${ }^{2} \cdot$ Gwanghui Ryu ${ }^{2}$ Su Jin $\mathrm{Kim}^{2} \cdot \mathrm{Kyung}$ Eun Lee ${ }^{2}$ \\ Hun-Jong Dhong ${ }^{2} \cdot$ Seung-Kyu Chung ${ }^{2}$
}

${ }^{l}$ Department of Otolaryngology, Keimyung University School of Medicine, Daegu; ${ }^{2}$ Department of Otorhinolaryngology-Head and Neck Surgery, Samsung Medical Center, Sungkyunkwan University School of Medicine, Seoul, Korea

Objectives. Compliance with continuous positive airway pressure (CPAP) treatment remains a primary concern for improving treatment outcomes of obstructive sleep apnea. There are few studies that have considered the role of upper airway anatomy on the compliance with CPAP. We hypothesized that upper airway anatomy would influence the compliance with CPAP.

Methods. One hundred out of 161 consecutive patients were enrolled in this study. The following possible determinants were tested against CPAP use: demographic and anthropometric data, minimal cross-sectional area on acoustic rhinometry, cephalometric and polysomnographic data, questionnaires of Epworth sleepiness scale and Beck depression index, and histories of previous upper airway surgery, degree of nasal obstruction, daily cigarette consumption, and weekly frequency of alcohol intake.

Results. Univariate analysis showed that histories of previous upper airway surgery and less frequent alcohol consumption, and longer mandibular plane-hyoid length (MP-H) on cephalometry were associated with longer average daily CPAP use. After adjustment for the confounding factors with multiple linear regression analysis, alcohol consumption and MP-H were still associated with the compliance with CPAP significantly.

Conclusion. To improve compliance with CPAP, careful evaluations of upper airway problems and life style are important before initiating CPAP.

Keywords. Obstructive Sleep Apnea; Continuous Positive Airway Pressure; Alcohol Drinking; Cephalometry

\section{INTRODUCTION}

Obstructive sleep apnea syndrome (OSAS) is characterized by a periodic reduction or cessation in airflow during sleep and daytime sleepiness, with a prevalence of $4.5 \%$ in men and $3.2 \%$ in

\footnotetext{
- Received December 30, 2015

Revised January 26, 2016

Accepted February 2, 2016

- Corresponding author: Hyo Yeol Kim

Department of Otorhinolaryngology-Head and Neck Surgery, Samsung

Medical Center, Sungkyunkwan University School of Medicine,

81 Irwon-ro, Gangnam-gu, Seoul 06351, Korea

Tel: +82-2-3410-3579, Fax: +82-2-3410-3879

E-mail: siamkhy@gmail.com
}

women of middle age [1]. OSAS is an emerging public health concern due to increases in the prevalence of obesity and the geriatric population, both of which are predisposing factors.

Continuous positive airway pressure (CPAP) is the first-line treatment in moderate to severe OSAS [2]. Appropriate use of CPAP can improve daytime sleepiness and abnormal sleep architecture, and prevent serious cardiovascular comorbidities [3]. Despite its reported effectiveness, compliance is relatively low and its efficacy depends on the patient's willingness to use the device and wear the nasal mask during sleep. The American Thoracic Society has indicated that the overall compliance rate approaches $50 \%$ at best, and it has been reported that most patients who discontinue CPAP therapy do so within the first few

Copyright (C) 2016 by Korean Society of Otorhinolaryngology-Head and Neck Surgery.

This is an open-access article distributed under the terms of the Creative Commons Attribution Non-Commercial License (http://creativecommons.org/licenses/by-nc/4.0)

which permits unrestricted non-commercial use, distribution, and reproduction in any medium, provided the original work is properly cited. 
months [4]. The major challenge for sleep physicians is, therefore, to increase the acceptance of, and compliance with, CPAP treatment. Various studies have reported on the adherence to, and compliance with, CPAP treatment, and have suggested possible predicting factors of CPAP compliance [5-7].

However, there are few studies that have considered the role of upper airway anatomy or lifestyle factors such as smoking or alcohol consumption in the compliance of CPAP. In the present study, we investigate the predicting factors of CPAP compliance, in particular upper airway anatomy and lifestyle factors in OSAS patients.

\section{MATERIALS AND METHODS}

\section{Subjects}

Consecutive adult patients from August 2010 to December 2013, who were confirmed to have OSAS by overnight polysomnography and were recommended CPAP treatment by the senior author (HYK) in the Department of Otorhinolaryngology-Head and Neck Surgery, were enrolled in the present study. Patients were excluded from this study if they had evidence of reduced cardiac function and/or chronic obstructive pulmonary disease at the time of the study or a previous history of a CPAP trial. Patients without enough data regarding anatomic or lifestyle parameters were also excluded from this study. The study was approved by the Institutional Review Board of Samsung Medical Center (IRB No. 2015-07-068).

At the initial visit, a medical history including demographic data and subjective symptoms was collected, and a full otorhinolaryngological evaluation including nose, oral cavity, and oropharynx was conducted. Age, gender, body mass index (BMI), daily amount of cigarette smoking, and weekly frequency of alcohol consumption were evaluated. Patients were also asked to quantify the degree of nasal obstruction they experienced on a scale ranging from $0-7$, according to the severity of the symptoms. A modified Mallampati score (MMS) and a tonsillar grade were assigned according to Friedman's classification, which has been described previously $[8,9]$. Cephalometry was performed in most of the participants, and the three following parameters were evaluated (Fig. 1): the palatal length (PL), which is the distance from the posterior nasal spine to the tip of the uvula; the

\section{H I G G H L L I}

- Multiple factors may influence continuous positive airway pressure (CPAP) compliance.

- In anatomical factors, longer mandibular plane-hyoid length is associated with better CPAP compliance.

- In life style factors, frequent alcohol consumption is associated with worse CPAP compliance.

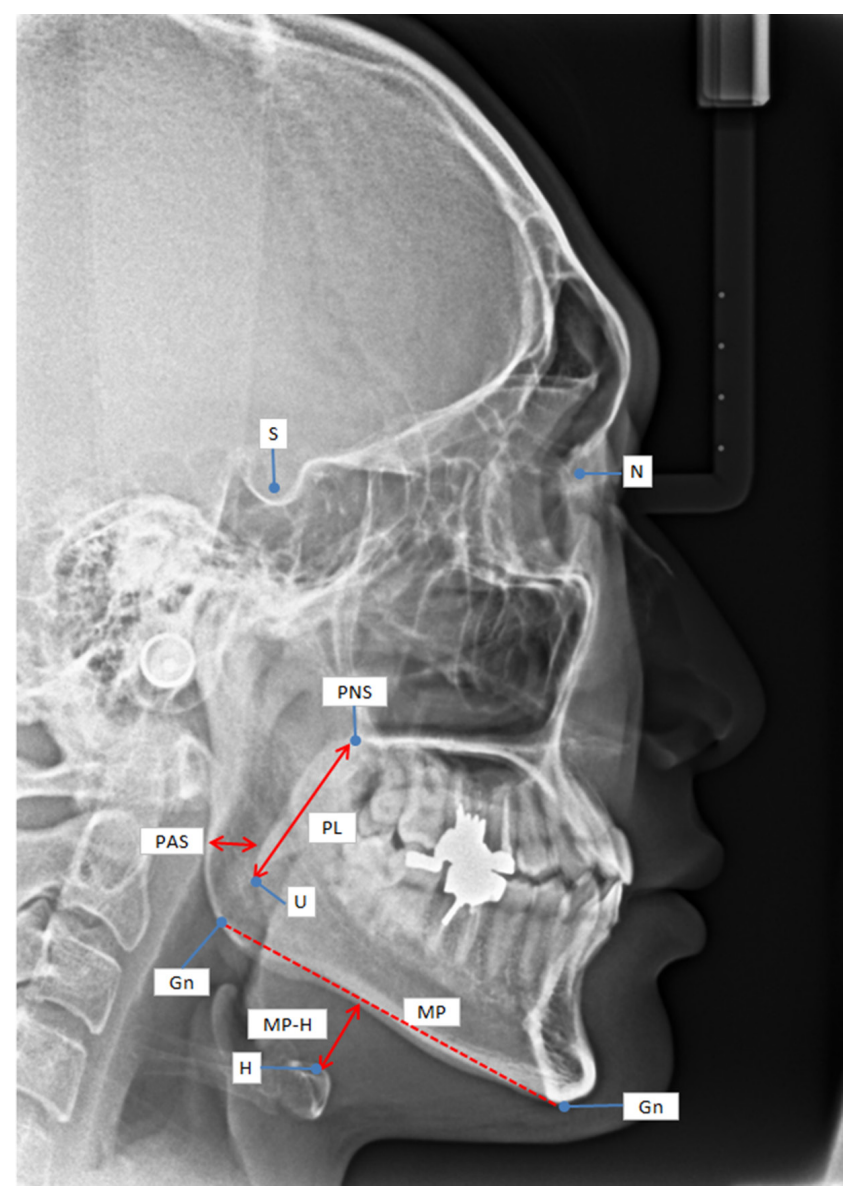

Fig. 1. Cephalometric parameters for obstructive sleep apnea syndrome. PL, palatal length; MP, mandibular plane; PAS, posterior airway space; H, hyoid bone; Go, gonion; Gn, gnathion; PNS, posterior nasal spine; $U$, uvula.

distance between the mandibular plane and the most anterosuperior point of the hyoid (MP-H); and the posterior airway space (PAS), which is the minimal distance between the tongue base and the posterior pharyngeal wall at the level of the mandibular angle.

In order to objectively evaluate the dimensions of the nasal cavity, acoustic rhinometry was performed [10]. The authors obtained the minimal cross-sectional area (MCA), defined as the smallest cross-sectional area in the nasal cavity, usually at the valleys on the anterior end of the inferior turbinate.

CPAP was recommended as a first-line treatment for severe OSAS, and was indicated for moderate to severe OSAS according to the results of a sleep study. In addition, patients with mild OSAS who wanted to use CPAP as a treatment were also enrolled in this study.

All patients had unattended auto-CPAP titrations for 2-3 weeks in the present study. They all received detailed instructions and 30-60 minutes of exposure to the CPAP machine to ensure a proper mask fit and acclimatization before the titration. Different types of CPAP nasal masks or nasal pillows were used 
according to facial structure and individual preference. Heated humidifiers were applied in all cases. A monitoring chip was placed in all of the CPAP devices and used to collect and store the CPAP use data. All patients were followed-up for more than three months after the start of CPAP treatment.

The monitoring chips provided varying information about CPAP use, including the days of CPAP use, the hours of daily use, and the presence of air leaks. We calculated the average daily CPAP use time at the end of the data collection period according to the following formula: average daily CPAP use $=$ total hours of CPAP use/number of follow-up days.

\section{Statistical analysis}

Using the data collected during the detailed interview, physical examination, cephalometry, acoustic rhinometry, and data from the monitoring chip, the following possible determinants were tested against CPAP use: demographic data (patient age, gender, and BMI), questionnaires and history (Epworth sleepiness scale [ESS], Beck depression index [BDI], history of upper airway surgery for snoring or nasal obstruction, presence of mouth breathing during polysomnography, degree of nasal obstruction, daily cigarette smoking, and weekly frequency of alcohol consumption), physical examination (tonsillar grade and MMS), acoustic rhinometry data (MCA), cephalometric data (PAS, MP$\mathrm{H}, \mathrm{PL}$ ) and total apnea and hypopnea index (AHI).

Statistical analyses were performed using SPSS ver. 13 (SPSS Inc., Chicago, IL, USA). Pearson correlation tests were used for continuous variables, and the Spearman correlation test was used to determine the relationship between categorical variables and the average daily CPAP use. A multiple regression test was used to statistically determine the relationships between average daily CPAP use and the variables that were found to be signifi- cant in the univariate analysis. The significance level was set at $P<0.05$ in all analyses.

\section{RESULTS}

During the study period, 161 consecutive patients were prescribed to start CPAP.Among the recruited patients, 26 declined to use CPAP after the first trial. Further, 6 more patients were excluded from this study due to follow-up loss and 29 patients were excluded because of incomplete history. Finally, a total of 100 patients were enrolled in the present study. The mean average CPAP use was $4.4 \pm 1.6$ hours/day. Participants were mostly male $(91 \%)$ with a mean age of $50.8 \pm 10.6$ years old. The mean BMI was 26.6 \pm 3.1 , and the total AHI ranged from 11 to 117 events/hour, with a mean of $44.8 \pm 21.6$ events/hour. Twentyfour patients $(24 \%)$ had a previous history of upper airway surgery for snoring or nasal obstruction.

Univariate analysis showed that certain variables were associated with average daily CPAP use, although age, gender, BMI, and AHI did not affect CPAP use. A history of upper airway surgery $(P=0.012)$ was associated with longer average daily CPAP use. Frequent alcohol consumption $(P=0.010)$ was associated with shorter average daily CPAP use. Anatomical variations were also associated with machine use. Longer MP-H $(P=0.015)$ were associated with longer average daily CPAP use. Even though they did not reach statistical significance, frequent cigarette smoking and a long posterior airway space had trends for shorter average daily CPAP use. Other anatomical variables including tonsillar grade or MMS and MCA showed no correlation with CPAP use (Tables 1, 2).

Even following adjustment for the confounding effects of each

Table 1. Univariate analysis of the possible predictors of the mean CPAP daily use

\begin{tabular}{|c|c|c|c|c|}
\hline Variable & Sample size & Mean $\pm S D$ & Correlation coefficient & $P$-value \\
\hline Age (yr) & 100 & $50.8 \pm 10.6$ & 0.121 & 0.156 \\
\hline Body mass index $\left(\mathrm{kg} / \mathrm{m}^{2}\right)$ & 100 & $26.6 \pm 3.1$ & -0.088 & 0.309 \\
\hline Apnea and hypopnea index (/hr) & 100 & $44.8 \pm 21.6$ & 0.040 & 0.636 \\
\hline Mild & 6 & $13.3 \pm 1.4$ & & \\
\hline Moderate & 28 & $23.5 \pm 4.2$ & & \\
\hline Severe & 66 & $56.7 \pm 18.3$ & & \\
\hline Epworth sleepiness scale & 100 & $10.2 \pm 4.4$ & 0.012 & 0.894 \\
\hline Beck depression index & 100 & $7.6 \pm 5.6$ & 0.187 & 0.138 \\
\hline Nasal obstruction & 100 & $3.2 \pm 1.8$ & -0.127 & 0.169 \\
\hline Daily cigarette smoking & 100 & $3.8 \pm 7.5$ & -0.203 & 0.053 \\
\hline Weekly alcohol consumption & 100 & $1.6 \pm 1.6$ & -0.343 & $0.010^{*}$ \\
\hline Minimal cross-sectional area $\left(\mathrm{cm}^{2}\right)$ & 100 & $1.3 \pm 0.4$ & -0.035 & 0.812 \\
\hline Posterior airway space (mm) & 100 & $12.4 \pm 3.4$ & -0.193 & 0.052 \\
\hline $\mathrm{MP}-\mathrm{H}(\mathrm{mm})$ & 100 & $18.9 \pm 5.6$ & 0.243 & $0.015^{\star}$ \\
\hline Palatal length (mm) & 100 & $42.5 \pm 4.5$ & -0.124 & 0.110 \\
\hline
\end{tabular}

CPAP, continuous positive airway pressure; $\mathrm{MP}-\mathrm{H}$, distance from the mandibular plane $(\mathrm{MP})$ to the hyoid bone $(\mathrm{H})$. ${ }^{\star} P$-value $<0.05$. 
Table 2. Mean daily CPAP use according to categorical variables

\begin{tabular}{lrcc}
\hline Characteristic & No. & CPAP (hr) & P-value \\
\hline Sex & & & 0.712 \\
$\quad$ Male & 91 & $4.4 \pm 1.8$ & \\
$\quad$ Female & 9 & $4.4 \pm 1.6$ & \\
Previous surgery & & & $0.012^{*}$ \\
Yes & 24 & $5.0 \pm 1.8$ & \\
No & 76 & $4.3 \pm 1.6$ & \\
Mouth breathing & & & 0.054 \\
Yes & 27 & $5.0 \pm 1.7$ & \\
No & 73 & $4.3 \pm 1.6$ & \\
Tonsillar grade & & & 0.252 \\
0 & 6 & $5.6 \pm 1.5$ & \\
1 & 53 & $4.5 \pm 1.7$ & \\
2 & 32 & $4.3 \pm 1.6$ & \\
3 & 9 & $4.3 \pm 1.9$ & \\
Modified Mallampati score & & & 0.850 \\
1 & 6 & $4.8 \pm 1.8$ & \\
2 & 38 & $4.3 \pm 1.6$ & \\
3 & 45 & $4.3 \pm 1.8$ & \\
4 & 11 & $4.9 \pm 1.9$ & \\
\hline
\end{tabular}

Values are presented as mean \pm SD.

CPAP, continuous positive airway pressure.

${ }^{*} P$-value $<0.05$.

variable on others, using multiple linear regression analysis, two (weekly alcohol consumption and MP-H) of these three variables still had significant relationships with average daily CPAP use (Table 3).

\section{DISCUSSION}

The present study shows that factors including upper airway anatomy, history of upper airway surgery, and alcohol consumption are associated with CPAP compliance according to univariate analysis. Using a multivariate regression method, MP-H and alcohol consumption were shown to be significant predictors of CPAP compliance following adjustment for the confounding effects of other variables.

Many researchers have studied the role of the upper airway in OSAS. Even though improved nasal breathing does not consistently improve OSAS itself, it can reduce daytime sleepiness and snoring [11-13]. Nasal obstruction usually causes mouth breathing during the day and night, which compromises adherence to CPAP therapy [14]. Improved nasal breathing can also decrease the CPAP pressure and improve the compliance with CPAP [15]. However, the effect of oral surgery for OSAS on CPAP compliance is still debated. Some studies have reported that air leaks at a lower CPAP level and reduction in the maximal level of pressure can be tolerated in the patients with uvulopalatopharyngoplasty (UPPP) compared with those who have not $[16,17]$. On the contrary, more recent studies have reported an improvement in CPAP use after multilevel surgery for OSAS
Table 3. Multiple regression analysis of the mean daily CPAP daily use

\begin{tabular}{lrcl}
\hline Variable & Coefficient & $\begin{array}{c}95 \% \text { confidence } \\
\text { interval }\end{array}$ & $P$-value \\
\hline Constant & 4.148 & 3.562 to 6.634 & 0.002 \\
PAS & -0.095 & -0.089 to -0.001 & 0.054 \\
MP-H & 0.079 & 0.024 to 0.134 & $0.005^{*}$ \\
Daily cigarette smoking & -0.049 & -0.046 to -0.001 & 0.042 \\
Weekly alcohol consumption & -0.326 & -0.519 to -0.132 & $0.001^{*}$ \\
\hline
\end{tabular}

Only significant data are shown.

CPAP, continuous positive airway pressure; MP-H, distance from the mandibular plane (MP) to the hyoid bone (H); PAS, posterior airway space. ${ }^{*} P$-value $<0.05$.

$[11,18]$. We found that patients with a history of upper airway surgery for OSAS or nasal obstruction use the CPAP machine significantly longer compared with those who have not undergone surgery.

Although still unclear, several factors have been suggested as the cause of this discrepancy. The first is the change in techniques and concepts for the surgical correction of OSAS. Previously, the main surgical treatment for OSAS was UPPP, a singlelevel surgery involving removal of the uvula and redundant tissue of the soft palate. However, it has evolved over the past decade from UPPP alone to a multilevel surgery, which addresses obstruction at the levels of the nose, palate, and hypopharynx. In addition, oral surgery in our department was performed in a modified way to retain part of uvula, unlike the classic UPPP, and preserve the sealing effect of the soft palate. Long-standing forced mouth breathing and subsequent mouth air leak can be relieved by this technique. Another assumption is that this discrepancy is due to the change in motivation to use CPAP. The patients in the present study were all managed by an ENT doctor who usually preforms OSAS surgery. Those who have undergone prior upper airway surgery may believe that another surgical treatment will not be useful for them, and may be more motivated regarding CPAP use because they realize that their treatment options are now limited [19].

We also found that a longer MP-H was associated with improved CPAP compliance. To the best of our knowledge, this is the first study focusing on the role of various upper airway structures in CPAP compliance. We do not know the reason for this. However, MP-H is considered to represent the size of the tongue or the length of the collapsible airway, and thus, patients with a longer MP-H may have a greater risk of obstruction during sleep in the supine position, thus an increased chance of benefit with CPAP.

Frequent alcohol consumption inhibited CPAP use in the present study, which is known from many studies to increase nasal resistance [20-22]. However, the role of alcohol as a predictor for CPAP compliance is still controversial. In terms of alcohol consumption, some researchers have reported that there is 
no association with CPAP use, while others have found a higher refusal rate of CPAP therapy with alcohol use [23-25]. Our results show that frequent alcohol consumption is associated with low CPAP compliance. The reason for this low compliance may be caused by a high skip-over CPAP therapy rate when the patient is drunk, and the Korean cultural difference of relatively frequent social drinking compared with Western countries.

Even though cigarette smoking did not reach statistical significance, it is also known to be associated with increased total nasal resistance, and Russo-Magno et al. [24] and Kim et al. [26] reported an association between cigarette smoking and noncompliance. In this study, smoking only had a trend for low average daily CPAP use without statistical significance.

Many studies have attempted to identify the predicting factors of CPAP compliance. While some studies have found relationships between age, gender, AHI, daytime sleepiness and CPAP compliance, these findings are inconsistent $[5,23,27-30]$. We did not find a significant role of age, gender, or physiological or symptomatic severity of OSAS (AHI and ESS) in CPAP compliance. Our study, as well as some of the previous studies, may have been subject to the usual caveats of having a very small number of women included in the study.

No association was found between CPAP compliance and the severity of OSAS or daytime sleepiness in the present study. The general consensus is that the results of sleep studies or self-reported daytime sleepiness do not predict the use of CPAP [29]. However, it should be noted that CPAP users with mild OSAS have a greater probability of being voluntary users than those with severe OSAS, because sleep physicians tend to recommend CPAP to the patients with severe OSAS with more confidence, introducing a confounding bias.

A diversity of factors may influence CPAP compliance including severity of disease, psychological factors, demographic factors, or obesity. The present study found that anatomical variations of the upper airway and other factors associated with the upper airway may influence CPAP compliance, suggesting a new direction of research. The upper airway, including the nose and pharynx, is the interface between the CPAP device and the lower airway. Structural variations or modifications will therefore have an effect on the communication between the upper and lower airways, which is illustrated by the report that preexisting nasal problems are related to lower adherence to the treatment [21]. It can be suggested from the results of the present study that careful evaluation and treatment of upper airway problems before initiating CPAP are important in the improvement of CPAP compliance.

In conclusions, a multitude of factors including anatomical variations of upper airway and frequent alcohol consumption may influence CPAP compliance, which empathizes the need for careful evaluations of upper airway problems and life style to improve CPAP compliance.

\section{CONFLICT OF INTEREST}

No potential conflict of interest relevant to this article was reported.

\section{REFERENCES}

1. Kim J, In K, Kim J,You S, Kang K, Shim J, et al. Prevalence of sleepdisordered breathing in middle-aged Korean men and women. Am J Respir Crit Care Med. 2004 Nov;170(10):1108-13.

2. Kushida CA, Littner MR, Hirshkowitz M, Morgenthaler TI, Alessi CA, Bailey D, et al. Practice parameters for the use of continuous and bilevel positive airway pressure devices to treat adult patients with sleep-related breathing disorders. Sleep. 2006 Mar;29(3):37580.

3. Giles TL, Lasserson TJ, Smith BH, White J, Wright J, Cates CJ. Continuous positive airways pressure for obstructive sleep apnoea in adults. Cochrane Database Syst Rev. 2006 Jul;(3):CD001106.

4. Indications and standards for use of nasal continuous positive airway pressure (CPAP) in sleep apnea syndromes. American Thoracic Society. Official statement adopted March 1944. Am J Respir Crit Care Med. 1994 Dec;150(6 Pt 1):1738-45.

5. Alves C, Caminha JM, da Silva AM, Mendonca D. Compliance to continuous positive airway pressure therapy in a group of Portuguese patients with obstructive sleep apnea syndrome. Sleep Breath. 2012 Jun;16(2):555-62.

6. Bakker JP, Marshall NS. Flexible pressure delivery modification of continuous positive airway pressure for obstructive sleep apnea does not improve compliance with therapy: systematic review and meta-analysis. Chest. 2011 Jun;139(6):1322-30.

7. Zozula R, Rosen R. Compliance with continuous positive airway pressure therapy: assessing and improving treatment outcomes. Curr Opin Pulm Med. 2001 Nov;7(6):391-8.

8. Friedman M, Ibrahim H, Joseph NJ. Staging of obstructive sleep apnea/hypopnea syndrome: a guide to appropriate treatment. Laryngoscope. 2004 Mar;114(3):454-9.

9. Kim HY, Min JY, Cho DY, Chung SK, Dhong HJ. Influence of upper airway narrowing on the effective continuous positive airway pressure level. Laryngoscope. 2007 Jan;117(1):82-5.

10. Kim HY, Dhong HJ, Hong SD, Lee HJ, Cho HJ, Chung SK. Paradoxical nasal obstruction: analysis of characteristics using acoustic rhinometry. Am J Rhinol. 2007 Jul-Aug;21(4):408-11.

11. Friedman M, Soans R, Joseph N, Kakodkar S, Friedman J.The effect of multilevel upper airway surgery on continuous positive airway pressure therapy in obstructive sleep apnea/hypopnea syndrome. Laryngoscope. 2009 Jan;119(1):193-6.

12. Li HY, Wang PC, Chen YP, Lee LA, Fang TJ, Lin HC. Critical appraisal and meta-analysis of nasal surgery for obstructive sleep apnea. Am J Rhinol Allergy. 2011 Jan-Feb;25(1):45-9.

13. Sufioglu M, Ozmen OA, Kasapoglu F, Demir UL, Ursavas A, Erisen $\mathrm{L}$, et al. The efficacy of nasal surgery in obstructive sleep apnea syndrome: a prospective clinical study. Eur Arch Otorhinolaryngol. 2012 Feb;269(2):487-94.

14. Bachour A, Maasilta P. Mouth breathing compromises adherence to nasal continuous positive airway pressure therapy. Chest. 2004 Oct; 126(4):1248-54.

15. Friedman M, Tanyeri H, Lim JW, Landsberg R, Vaidyanathan K, Caldarelli D. Effect of improved nasal breathing on obstructive sleep apnea. Otolaryngol Head Neck Surg. 2000 Jan;122(1):71-4.

16. Han F, Song W, Li J, Zhang L, Dong X, He Q. Influence of UPPP surgery on tolerance to subsequent continuous positive airway pres- 
sure in patients with OSAHS. Sleep Breath. 2006 Mar;10(1):37-42.

17. Mortimore IL, Bradley PA, Murray JA, Douglas NJ. Uvulopalatopharyngoplasty may compromise nasal CPAP therapy in sleep apnea syndrome. Am J Respir Crit Care Med. 1996 Dec;154(6 Pt 1):1759-62.

18. Chandrashekariah R, Shaman Z, Auckley D. Impact of upper airway surgery on CPAP compliance in difficult-to-manage obstructive sleep apnea. Arch Otolaryngol Head Neck Surg. 2008 Sep; 134(9): 926-30.

19. Hong SD, Kim HY, Cho HJ, Jang MS, Dhong HJ, Chung SK. Effect of uvulopalatopharyngoplasty on CPAP compliance. Eur Arch Otorhinolaryngol. 2015 Jun;272(6):1437-42.

20. Eccles R, Tolley NS. The effect of alcohol ingestion upon nasal airway resistance. Rhinology. 1987 Dec;25(4):245-8.

21. Mitler MM, Dawson A, Henriksen SJ, Sobers M, Bloom FE. Bedtime ethanol increases resistance of upper airways and produces sleep apneas in asymptomatic snorers. Alcohol Clin Exp Res. 1988 Dec; 12(6):801-5.

22. Series F, Cormier FY, Desmeules M. Alcohol and the response of upper airway resistance to a changing respiratory drive in normal man. Respir Physiol. 1990 Aug;81(2):153-63.

23. McArdle N, Devereux G, Heidarnejad H, Engleman HM, Mackay TW, Douglas NJ. Long-term use of CPAP therapy for sleep apnea/ hypopnea syndrome. Am J Respir Crit Care Med. 1999 Apr;159(4 Pt 1):1108-14.

24. Russo-Magno P, O’Brien A, Panciera T, Rounds S. Compliance with CPAP therapy in older men with obstructive sleep apnea. J Am Geriatr Soc. 2001 Sep;49(9):1205-11.

25. Wild MR, Engleman HM, Douglas NJ, Espie CA. Can psychological factors help us to determine adherence to CPAP? A prospective study. Eur Respir J. 2004 Sep;24(3):461-5.

26. Kim SJ, Choi JH, Kim EJ, Lee SK, Lee SH, Jun YJ, et al. A prospective population-based study of total nasal resistance in Korean subjects. Clin Exp Otorhinolaryngol. 2012 Mar;5(1):39-43.

27. Bollig SM. Encouraging CPAP adherence: it is everyone's job. Respir Care. 2010 Sep;55(9):1230-9.

28. Ball EM, Banks MB. Determinants of compliance with nasal continuous positive airway pressure treatment applied in a community setting. Sleep Med. 2001 May;2(3):195-205.

29. Lewis KE, Seale L, Bartle IE, Watkins AJ, Ebden P. Early predictors of CPAP use for the treatment of obstructive sleep apnea. Sleep. 2004 Feb;27(1):134-8.

30. Sin DD, Mayers I, Man GC, Pawluk L. Long-term compliance rates to continuous positive airway pressure in obstructive sleep apnea: a population-based study. Chest. 2002 Feb;121(2):430-5. 